\title{
Stray dog trade fuelled by dog meat consumption as a risk factor for rabies infection in Calabar, southern Nigeria
}

\author{
*Ekanem EE ${ }^{1}$, Eyong $\mathrm{KI}^{1}$, Philip-Ephraim EE², Eyong $\mathrm{ME}^{1}$, Adams EB ${ }^{1}$, Asindi $\mathrm{AA}^{1}$ \\ 1. Department of Paediatrics, University of Calabar. \\ 2. Department of Internal Medicine, University of Calabar
}

\begin{abstract}
Background: Rabies is a preventable zoonosis with the highest case fatality of any disease in the world. In the developing world, it is transmitted mainly by dog bites. In parts of southern Nigeria, dog meat is a delicacy.

Objective: To highlight trade in stray dogs as a major risk factor for rabies in animals and humans in south-south Nigeria. Method: Patients admitted into the University of Calabar Teaching Hospital (UCTH) with a diagnosis of rabies between July and October 2012 were analysed for risk factors, post exposure prophylaxis (PEP), health seeking behaviour and outcome. Focused group interview were also conducted among traders/ handlers of stray dogs.

Results: Ten cases of rabies in subjects aged 3 to 52 years were recorded in these five months period. Eight of the cases were male and apparently got infected directly or indirectly through the trade in stray dogs for human consumption. None had proper PEP and all patients died.

Conclusion: Stray dog trade, fuelled by eating of $\mathrm{dog}$ meat, is a risk factor for human and animal rabies in Calabar, southern Nigeria. Culling of stray dogs, control of stray dogs' trade and public enlightenment on PEP is recommended.

African Health Sciences 2013; 13(4): 1170 - 1173 http://dx.doi.org/10.4314/ahs.v13i4.44
\end{abstract}

\section{Introduction}

Rabies is a preventable viral disease of mammals most often transmitted through the bite of a rabid animal. In the past, human rabies usually resulted from a dog bite, but recently, more cases of human rabies have been linked to bats, cats and raccoons ${ }^{1}$. In the developing world, dog bites are still the commonest cause of rabies ${ }^{2}$.

Rabies is universal. According to WHO report in 2006, more than 3.3 billion people are at risk for rabies in over 85 countries worldwide ${ }^{3,4}$.

About 55000 deaths from rabies are estimated to occur every year, $99 \%$ of which are the consequence of dog bites ${ }^{5,6}$ Of these 31000 are estimated to occur in Asia (20 000 in India alone) and 24000 in Africa.

Universally no disease exceeds the case fatality rate of rabies. Progress must continue towards the elimination of human rabies. ${ }^{7}$

In countries where rabies is endemic, stray dogs account for more than $90 \%$ of human rabies exposures, especially among 5-14 years old children in rural or peri-urban areas 8 .

\section{*Corresponding author: \\ Prof Emmanuel E Ekanem \\ Department of Paediatrics \\ University of Calabar \\ Phone No: +234 80222907609 \\ Email: profekanem@gmail.com}

In parts of southern Nigerian, dog meat is a widely consumed delicacy. In recent times we have recorded a number of cases of rabies associated with bites and scratches from such dogs bought for consumption.

The purpose of this report is to highlight the transportation and wide consumption of stray dogs in southern Nigeria as a risk factor for rabies and cruelty to animals; and alert the authorities on the need for the control of this trade and threat to human life.

\section{Methods}

The subjects were children and adults admitted to the University of Calabar Teaching Hospital (UCTH), Calabar with a clinical diagnosis of rabies. The hospital serves as a referral centre for the whole of Cross River State, in southern Nigeria. Cross River State has a population of 2.9 million $^{9}$

The demographic data of the patients; parents' occupation, health seeking behaviour of the patients / parents, the clinical features at presentation, modalities of treatment before presentation, nature of attacks, and immunization status of the dogs and the outcome of the patients were documented. Through careful history, the sources of the infections were determined. Focus group interviews of the participants in the stray dog trade was also conducted 
to determine the sources of the dogs and their handling.

Each patient was treated with intravenous alimentation, sedation and other supportive measures.

\section{Results}

Table 1 shows a summary of the features of the ten cases of rabies seen in the UCTH between July and October 2012. Focus group interviews of persons involved in the trade revealed that such dogs are usually stray dogs captured in northern Nigeria mainly Adamawa, Bauchi and Plateau states and transported in large numbers in trucks to the south for consumption. ones are selected for domestication. These ones often go into fights with the local ones. Others are tied and killed with blows to the head, before being roasted and prepared for eating.

Serial number 1 was bitten by a domesticated dog which suddenly turned violent and was immediately killed and eaten. The father of serial number 3 is a dealer in stray dogs and dog meat and the child was bitten by one of the stray dogs meant for sale. The others were earlier bitten by domesticated dogs which had earlier had fights with stray dogs (serial nos. 2,3, 7 and 8). Serial number 6 was bitten by an unidentified stray dog while serial

Table 1: Summary of demographic and clinical features of rabies seen in UCTH

\begin{tabular}{|c|c|c|c|c|c|c|}
\hline $\begin{array}{l}\text { Serial } \\
\text { number }\end{array}$ & $\begin{array}{l}\text { Age } \\
\text { (years) }\end{array}$ & Sex & place of first & $\begin{array}{l}\text { modality of treatment } \\
\text { before presentation }\end{array}$ & $\begin{array}{l}\text { Incubation } \\
\text { period }\end{array}$ & Clinical symptoms \\
\hline 1 & 3 & $\mathrm{~F}$ & $\begin{array}{l}\text { Traditional } \\
\text { medicine }\end{array}$ & Herbal concoction & 1 month & $\begin{array}{l}\text { Irrational behaviour Hydrophobia } \\
\text { Aerophobia }\end{array}$ \\
\hline 2 & 5 & M & Chemist & $\begin{array}{l}\text { Injections/oral } \\
\text { medications }\end{array}$ & 1 month & $\begin{array}{l}\text { Irrational behaviour Hydrophobia } \\
\text { Aerophobia }\end{array}$ \\
\hline 3 & 8 & M & None & Nil & 3 month & $\begin{array}{l}\text { Hydrophobia Aerophobia Muscle } \\
\text { spasms, Dysphagia }\end{array}$ \\
\hline 4 & 8 & M & None & $\mathrm{Nil}$ & 2 months & $\begin{array}{l}\text { Hydrophobia, Muscle spasms, Muscular } \\
\text { pain }\end{array}$ \\
\hline 5 & 10 & M & Chemist & Oral antibiotics & 1 month & Hydrophobia Aerophobia \\
\hline 6 & 25 & $\mathrm{~F}$ & none & $\mathrm{Nil}$ & 2 months & Excessive salivation, Hydrophobia \\
\hline 7 & 25 & M & Chemist & $\begin{array}{l}\text { Wound dressing } \\
\text { antibiotics }\end{array}$ & 3 Months & Hydrophobia, Barking sounds \\
\hline 8 & 27 & M & None & Nil & 3 months & $\begin{array}{l}\text { Hydrophobia, muscle spasms, muscular } \\
\text { pain }\end{array}$ \\
\hline 9 & 40 & M & None & Nil & 3 months & $\begin{array}{l}\text { Hydrophobia, Mutism } \\
\text { Aerophobia Headache }\end{array}$ \\
\hline 10 & 52 & M & Chemist & Antibiotics & 3 months & Dyspnoea, Hydrophobia \\
\hline
\end{tabular}

The dealers in dog business seem to be aware of rabies and claimed to have an organ within the dog's abdomen which when eaten, serves as prophylaxis against rabies. They insisted this was a trade secret which could not be revealed.

The traders take measures to circumvent veterinary checks on the way during the transportation of the dogs. Such animals usually arrive from the long distance journey un-fed, exhausted and irritable. Some of the bigger, healthier number 9 and 10 were bitten by stray dogs meant for sale.

Almost all the victims either first presented to chemists shop or to no health facility at all. One first presented to a traditional medicine man. None had post exposure prophylaxis. 


\section{Discussion}

Rabies is universal with almost uniform mortality. Recently survival rate of $8 \%$ has been claimed in the United States. ${ }^{10}$

The ten cases of rabies reported within five months in a referral centre which serves a population of only 2.9 million is an epidemic and may represent a tip of the iceberg. The major risk factor for rabies in this series was the widespread trade of stray dogs fuelled by consumption of dog meat as a delicacy. All of the dogs meant for consumption are usually strayed, apparently unimmunized, posing a threat to those involved in the trade. The states in Nigeria from where these dogs are captured are known to be endemic for rabies from dog bites. ${ }^{11,12}$ Rabies could easily have entered the food chain in Cross River State from these sources. The prophylaxis claimed by the dealers is obviously spurious.

Since this trade is usually carried out within or near living quarters, children are also exposed.

The preponderance of males in this study may be a reflection of the fact that the trade is carried out almost exclusively by males. Male children are also more adventurous and therefore more likely to encounter these animals.

The study also observed poor health seeking behaviour in all the subjects.

Six of the ten cases reported did not present to any health care facility following the bites, while the other four visited patent medicine stores and drug vendors for first aid.

Post exposure prophylaxis with anti-rabies vaccine is the major preventive measure against rabies following a bite by a rabid animal. ${ }^{13}$

None of the victims had prophylaxis, as none presented to an appropriate health facility until the onset of symptoms. It is also obvious that the patients/parents had no knowledge of the implication of such bites or the appropriate prophylaxis.

In our environment, roadside chemists play major roles in health care as they are closer to the people, cheaper and poorly regulated. These chemists have no formal training and learn by apprenticeship with older chemists. It is evident that they either do not know the significance of bites by stray dogs and/or the proper post exposure prophylaxis.

In addition, the capture of dogs and transportation for several hours in congested trucks without food or water, and killing with blows to the head amount to cruelty to animals and should not be tolerated. However the practice is wide spread and deeply rooted and would not be easily eliminated.

\section{Conclusion}

Trade in stray dogs, fuelled by consumption of dog meat as a delicacy, is a major risk factor for exposure to rabies in our environment. Poor health seeking behaviour and inappropriate post-exposure prophylaxis lead to clinical disease which is uniformly fatal.

\section{Recommendations}

It is recommended that stray dogs be culled in this and similar environment. The inspection of premises to ascertain the immunization status of dogs, which used to be a standard practice in Nigeria, should be re-introduced for reason of human and animal safety. This trade in stray dogs should be regulated. It is important to also make known to the public, through all available mass media outlets, the significance of bites by stray dogs and the need and place for proper post-exposure prophylaxis.

Post exposure vaccine for rabies should be considered for persons and families of participants in dog meat business. The vaccine by intradermal route has been proven to be economical, safe and immunogenic in populations of rabies endemic areas. The immunity produced by three-dose series is longlasting. ${ }^{14}$

\section{Acknowledgement}

We are grateful to the nurses and resident doctors who participated in the management of these children. We are also grateful to the traders who were willing to give us information.

\section{Limitations of the study}

The practice of killing and eating dogs when they bite has made it impossible to obtain the dogs brain for confirmation of rabies. Also all the cases were diagnosed clinically without laboratory confirmation. However the clinical features of rabies are unmistakable.

Secondly, the well-known resistance to autopsy examination made it impossible for us to examine the victims' brains; however, the clinical features were clear enough for the diagnosis of rabies. 


\section{References}

1. CDC. Rabies in the US. www cdc.gov/rabies/ location/usa. Assessed : 20-09-2013

2. Rupprecht CE, Briggs D, Brown CM. Center for Disease Control and Prevention (CDC). Use of a reduced (4-dose) vaccine schedule for postexposure prophylaxis to prevent human rabies: recommendations of the advisory committee on immunization practices. MMWR. Recomm. Rep. 2010;19: 59

3. World Health Organization (WHO). Expert Consultation on Rabies. Geneva 2004: 5-8.

4. World Health Organization (WHO). Rabies Facts in short. Geneva 2006: 4-7.

5. Meslin FX, Fishbein DB, Matter HC. Rationale and prospects for rabies elimination in developing countries. Curr. Top. Microbiol. Immunol. 1994;187:1-26.

6. Knobel DL, Cleaveland S, Coleman PG, Fevre EM, Meltzer MI, Miranda ME. Re-evaluating the burden of rabies in Africa and Asia. Bull. Wld. Hlth. Org. 2005; 83:360-8.

7. World Health Organization (WHO). Guidelines for oral vaccination of dogs against rabies without cover. Geneva.2007; 5:6-8.

8. Sudarshan MK, Madhusudana SN, Mahendra BJ, Rao NS, Ashwath DH, Abdul Rahman S. Assessing the burden of human rabies in India: results of a national multi-centre epidemiological survey. Int. J. Infect. Dis.2007; 11:29-35.

9. Federal republic of Nigeria population census. National Bureau of statistics. 2006.

10. Willoughbyja R E. Are we getting closer to the treatment of rabies? Neurology 2009;4:563-570.

11. Ezeokoli CU, Umoh JJ. Epidemiology of rabies in northern Nigeria. Trans $\mathrm{R}$ Soc Med Hyg 1987;81: 268 -272.

12. Karshima NS, Kujul NB, Ogbu KI, Abdullateaf MH,Dung PA,Salihu AA, et al. Incidence and risk factors associated with rabies and dog bites among dogs involved in bites in plateau state, Nigeria between 2011 and 2012. Anim Sci Adv; 2013; 3(3): 114-120

13. Nagarajan T, Rupprecht CE, Dessain SK, Rangarajan PN, Thiagarajan D, Srinivasan VA. Human monoclonal antibody and vaccine approaches to prevent human rabies Curr. Top. Microbiol. Immunol. 2008; 317:67-101.

14. Phillippe G, Phillippe P. Rabies Pre-treatment vaccination. Curr. Opin. Infect. Dis. 2012; 25:500-

6. 